15

\title{
Плазмохимический реактор на основе импульсного дугового разряда низкого давления для синтеза нанопорошков
}

\author{
(C) И.В. Карпов, ${ }^{1,3}$ А.В. Ушаков, ${ }^{1,3}$ А.А. Лепешев, ${ }^{1,2}$ Л.Ю. Федоров ${ }^{1}$ \\ ${ }^{1}$ Сибирский фредеральный университет, \\ 660041 Красноярск, Россия \\ ${ }^{2}$ Красноярский научный центр СО РАН, \\ 660036 Красноярск, Россия \\ ${ }^{3}$ Сибирский государственный аэрокосмический университет им. акад. М.Ф. Решетнева, \\ 660123 Красноярск, Россия \\ e-mail: sfu-unesco@mail.ru
}

(Поступило в Редакцию 12 апреля 2016 г.)

Рассмотрено устройство для получения нанопорошков в плазме дугового разряда низкого давления. Работа устройства основана на использовании в качестве источника плазмы импульсного дугового испарителя с холодным катодом. Описаны особенности конструкции и принцип действия устройства. Представлены экспериментальные данные по влиянию давления газовой смеси в реакторе на свойства нанопорошков.

DOI: $10.21883 /$ JTF.2017.01.44031.1851

\section{Введение}

В настоящее время в материаловедении и в промышленности возрастает интерес к разработке оборудования для получения и исследования нанопорошков (НП) [14]. Это связано с тем, что малые размеры частиц, высокая химическая активность и энергонасыщенность НП металлов и химических соединений позволяет их использовать при создании материалов с уникальными свойствами в следующих направлениях и областях техники: получение многокомпонентной керамики, металлокерамики, а также катализаторов, сорбентов, пигментов, селективных газопоглотителей, присадок к смазочным маслам, магнитных жидкостей и магнитных носителей записи информации, модификаторов порошковых сплавов, абразивных порошков, носителей лекарственных форм и т.д. [5].

Реализация плазменных технологических процессов в вакууме открывает качественно новые возможности в технологии получения НП. Обеспечивается высокая чистота, принципиально необходимая для получения НП, открываются широкие возможности для генерации активных плазм, управления ими при помощи электрических и магнитных полей с последующим получением НП методом конденсации из плазменной фазы. Причем такие параметры, как высокие температура и степень ионизации плазмы, оказывают существенное влияние на дисперсность получаемых НП. Изменение энергии частиц в процессе конденсации позволит получать различные структуры конкретного материала от аморфных до кристаллических, при этом размеры и форма кристаллов меняются в зависимости от энергии. При смешивании ряда активных плазм открываются возможности проведения плазмохимических реакций прямого синтеза сложных веществ, более того, реакции происходят без выхода побочных продуктов. В связи с этим задача создания оборудования для получения НП в плазме дугового разряда низкого давления является весьма актуальной.

Из всего многообразия плазменных технологических процессов распыления металлов в вакууме, на наш взгляд, наиболее перспективным является использование импульсных дуговых разрядов [6,7].

Использование импульсных дуговых разрядов позволяет относительно просто изменять энергию и длительность импульса, а также частоту повторения импульсов, что дает широкие возможности для выбора вида испаряемых материалов и управления производительностью метода.

При синтезе НП [8-11] методом испарения и конденсации длительность импульса дугового разряда должна, с одной стороны, быть меньше времени образования на мишени сплошной жидкой ванны, а с другой стороны, обеспечивать введение энергии, достаточной для испарения материала (в том числе тугоплавкого) и создания достаточно низкой плотности паров для исключения объединения получаемых частиц. При использовании импульсных дуговых разрядов, энергии ионов в которых обычно не более $10 \mathrm{eV}$, а характерное значение тока в импульсе не превышает $3 \mathrm{kA}$, указанные условия по энергии пучка ионов достигаются, если длительность пучка ограничена пределами от 20 до $300 \mu \mathrm{s}$. При этом плотность тока на катоде должна бы не менее $10^{8} \mathrm{~A} / \mathrm{cm}^{2}$ для испарения большей части материала в режиме абляции $[12,13]$. При этом полностью исключить создание жидкой ванны на мишени, а следовательно, и выброса капель из мишени невозможно, исходя из физики поглощения энергии электронного пучка материалом, носящего нелинейный характер.

Расширение в газ низкого давления позволяет получить высокие скорости расширения, обеспечивающие быстрое снижение концентрации паров и получение 
частиц малых размеров. При этом наличие газа позволяет осуществлять достаточно быстрое охлаждение закалку частиц порошка за счет не только радиационного, как в вакууме, но и молекулярного механизма теплообмена [14].

\section{1. Конструкция и принцип работы плазмохимического реактора}

Установка создана на базе модернизированной ионноплазменной установке ННВ-6.6-И1 и состоит (рис. 1) из вакуумной камеры 1 , в которой на боковой стенке установлен специально разработанный импульсный дуговой испаритель металла 2. Импульсный дуговой испаритель 2 (рис. 2) состоит из цилиндрического охлаждаемого расходуемого катода 3 с пристыкованным к нему тоководом 4 для подачи электропитания и охлаждающей жидкости, коаксиального охлаждаемого анода 5, прикрепленного к катоду 3 с помощью фторопластового изолятора, системы подмагничивания 6, установленной внутри анода 5, анода 7, совмещенного с цилиндрической охлаждаемой поверхностью конденсации, установленной с возможностью вращения, поджигающего электрода 8 . Электропитание дежурной дуги осуществляется при помощи системы питания 9, „минус“ питания которой подключен через систему подмагничивания 6 к токоподводу 4 , а „плюс“ питания к коаксиальному аноду 5. Электропитание импульсной сильноточной дуги осуществляется при помощи системы питания 10, „общий“ провод которой подключен к аноду 7, а отрицательные импульсы подаются через систему подмагничивания 6 на токоподвод 4. Электропитание поджигающего электрода 8 осуществляется при помощи системы питания 11, подключенной к токоподводу поджигающего электрода. У поверхности конденсации установлен механизм съема 12 образующегося порошка. Для сбора порошка в нижней части вакуумной камеры установлен бункер 14. В верхней части вакуумной камеры 1 установлена система подачи плазмообразующего и реакционного газов.

Установка работает следующим образом. После достижения в вакуумной камере давления $1.33 \cdot 10^{-3} \mathrm{~Pa}$, при помощи системы подачи реакционного газа устанавливается необходимое давление от 0.1 до 200 Ра. Включаются системы питания 9, 10 и 11. На поджигающий электрод 8 при помощи системы питания 11 подается высоковольтный импульс с амплитудой $25 \mathrm{kV}$. В результате пробоя пространство между катодом 3 и анодом 5 оказывается ионизованным, что облегчает зажигание дежурной дуги. Дежурный дуговой разряд между катодом 3 и анодом 5 поддерживается при помощи системы питания 9. В результате загорания дежурной дуги пространство между катодом 3 и анодом 7 оказывается ионизованным, что облегчает зажигание импульсной сильноточной дуги. Импульсный дуговой разряд поддерживается при помощи системы питания 10. Система подмагничивания

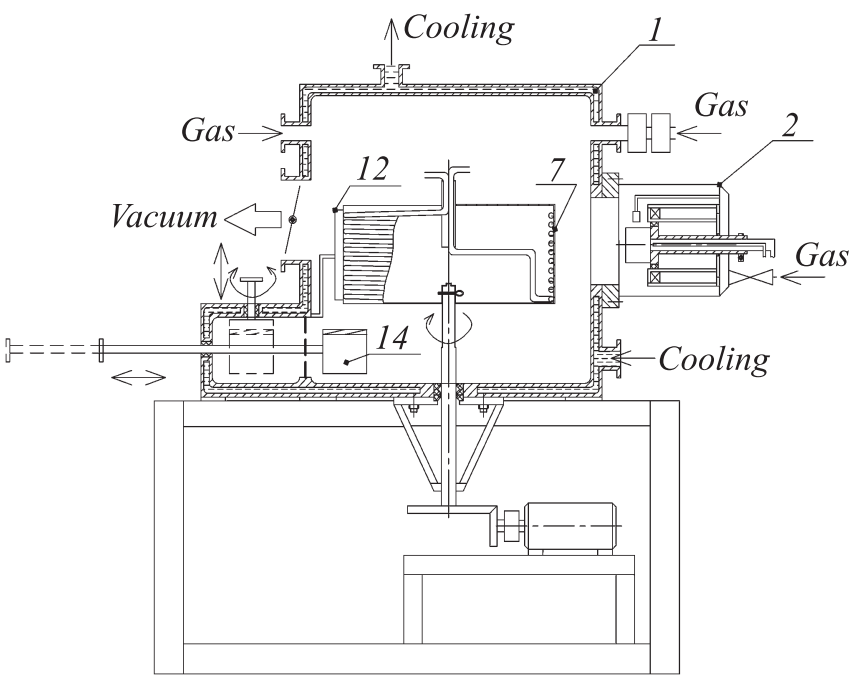

Рис. 1. Установка для получения нанопорошков в плазме дугового разряда низкого давления. Пояснение обозначений в тексте.

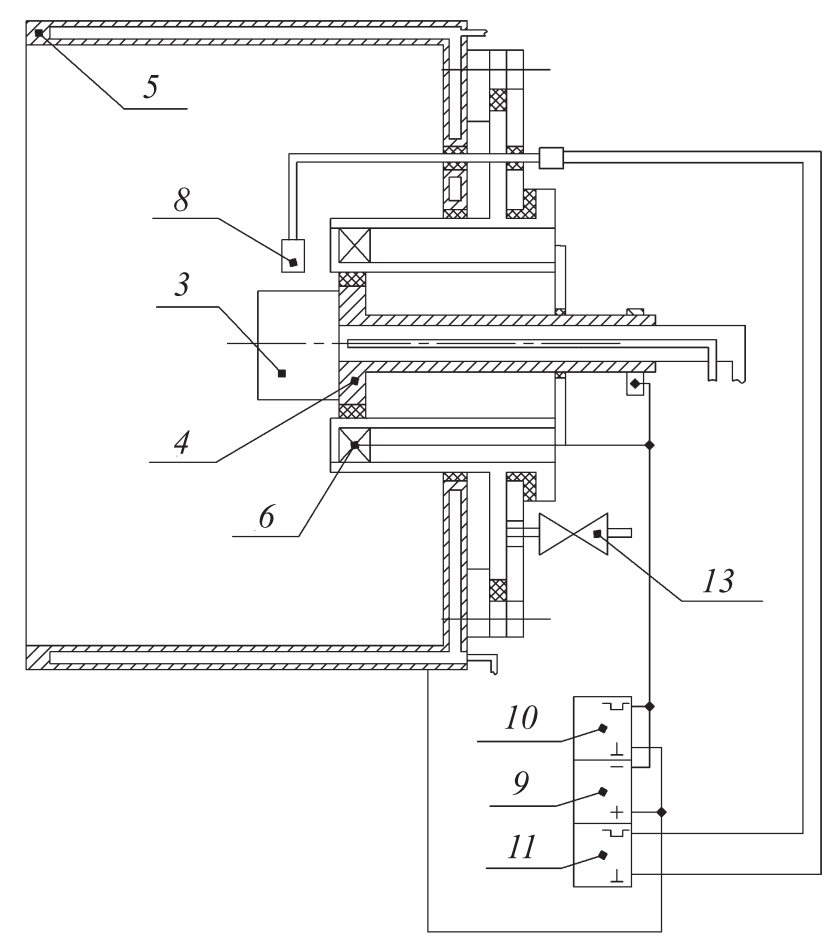

Рис. 2. Импульсный дуговой испаритель с холодным катодом. Пояснение обозначений - в тексте.

6 включена в токовую цепь катода 3 и служит для стабилизации работы дугового испарителя. В процессе испарения материала катода в дуговом разряде паровой поток поступает на вращающуюся охлаждаемую поверхность конденсации 7, осаждается на ней и в виде порошка снимается устройством 12. Полученный порошок собирается в бункере 14. Установка позволяет получать порошки как чистых металлов, так и 

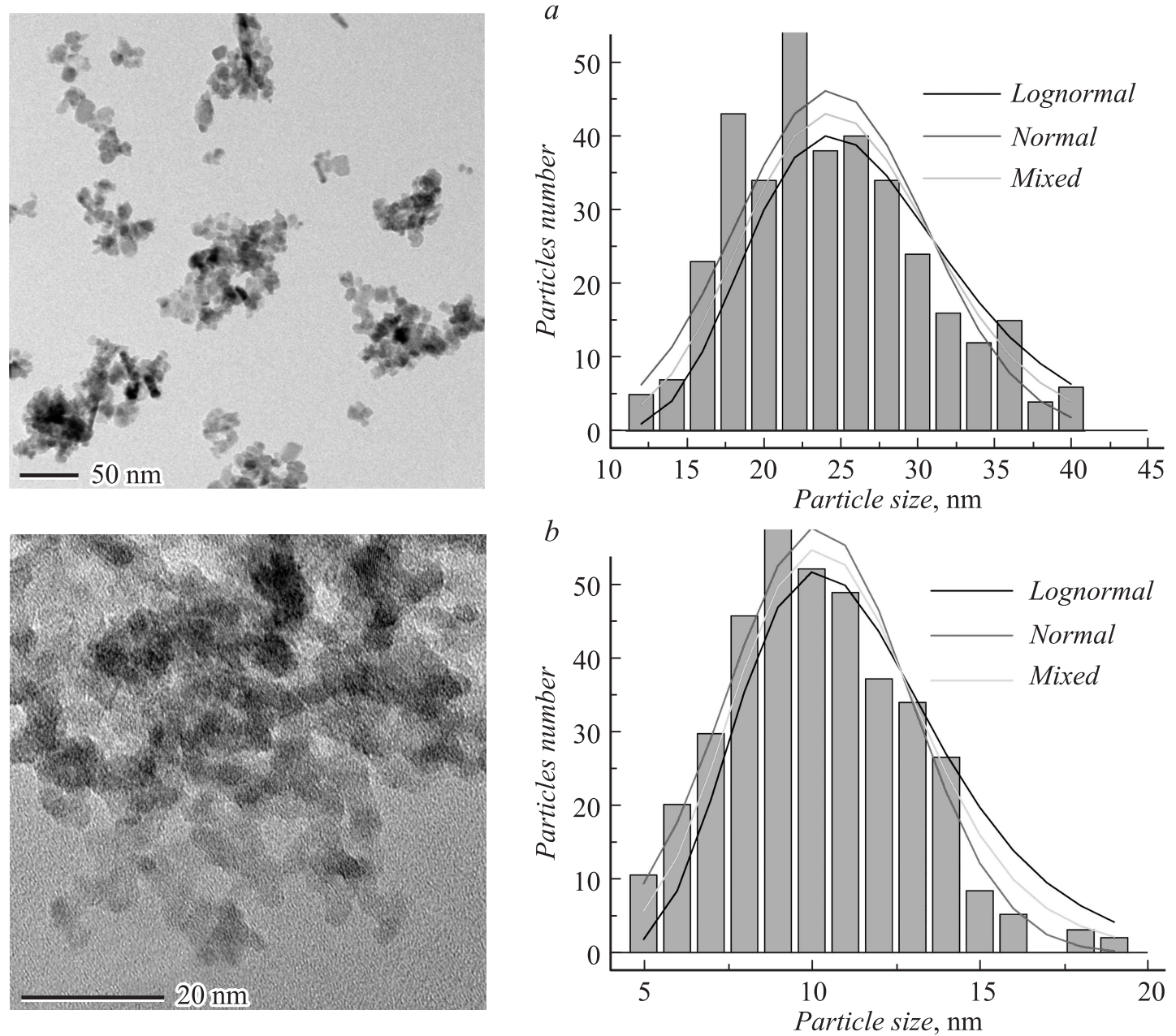

Рис. 3. ТЕМ фотографии, гистограммы и функции плотности вероятности нанодисперсных порошков Сu $\mathrm{O}_{2}$, полученные при давлении газовой смеси $10 \mathrm{vol} . \% \mathrm{O}_{2}+90 \% \mathrm{~N}_{2}$ при: $a-10, b-50, c-80, d-150 \mathrm{~Pa}$.

химические соединения металла с кислородом, азотом и углеродом, для чего предусмотрена система подачи плазмообразующего и реакционного газов.

\section{2. Методика проведения параметрических испытаний устройства}

Параметрические испытания устройства осуществлялись следующим образом. В качестве распыляемого катода была использована медь электролитического рафинирования М0 с диаметром $80 \mathrm{~mm}$ и длиной $100 \mathrm{~mm}$. Импульсный дуговой разряд с частотой $1 \mathrm{kHz}$, длительностью импульса $250 \mu \mathrm{s}$ и амплитудой тока в импульce $2.3 \mathrm{kA}$ поддерживался при помощи системы питания. Реактор предварительно вакуумировали до базового давления $10^{-3} \mathrm{~Pa}$. В качестве плазмообразующего газа использовался аргон, который подавался через испаритель и создавал в камере базовое давление. Для исследования влияния давления синтез наночастиц проводился при базовом давлении $10,50,80,140$ и $200 \mathrm{~Pa}$. В качестве реакционного газа использовались кислород и азот. Синтез наночастиц исследовался при скорости потока для кислорода $10 \mathrm{vol} . \%$, для остальных газов $30 \mathrm{vol} . \%$ от подачи плазмообразующего газа. Кислород подавался в реактор таким образом, чтобы образовать однородную оболочку вокруг плазменного факела. Продукты реакции осаждали в течение $10 \mathrm{~min}$ на вращающуюся охлаждаемую поверхность конденсации, расположенную на расстоянии $0.12 \mathrm{~m}$ от катода.

Морфологический состав исследуемых образцов изучался на просвечивающем электронном микроскопе JEOL JEM-2100. Исследование фазового состава полученных образцов проводили с помощью рентгеновского дифрактометра Advance D8 в $\mathrm{Cu} K_{\alpha}$ монохроматизированном излучении. Сканирование проводилось при комнатной температуре в интервале углов 30-120 deg по $2 \theta$ шагом $0.06 \mathrm{deg}$. Количественный структурно-фазовый анализ дифрактограмм проведен с помощью программы полнопрофильного анализа Powder Cell 2.4. Для идентификации рентгеновских спектров использованы базы данных PDF4+. 

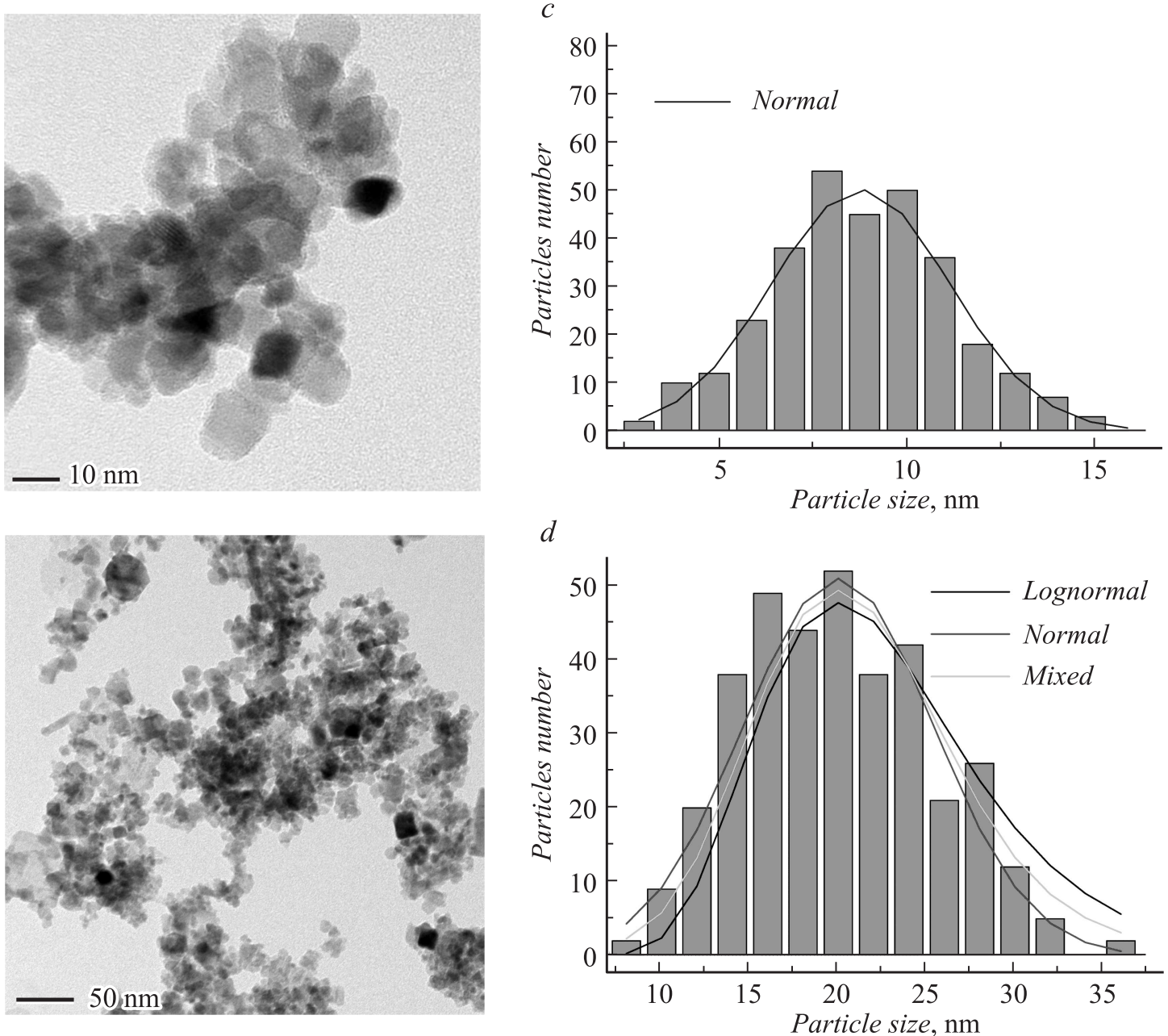

Рис. 3 (продолжение).

Основные параметры вероятностного распределения частиц по размерам

\begin{tabular}{c|c|c|c|c|c}
\hline $\begin{array}{c}\text { Давление газовой } \\
\text { смеси, Ра }\end{array}$ & $\begin{array}{c}\text { Диапазон частиц, } \\
\mathrm{nm}\end{array}$ & $\begin{array}{c}\text { Средний размер } \\
\text { частиц, } \mathrm{nm}\end{array}$ & $\begin{array}{c}\text { Среднемассовый } \\
\text { размер, } \mathrm{nm}\end{array}$ & $\begin{array}{c}\text { Среднеквадратичное } \\
\text { отклонение }\end{array}$ & $\begin{array}{c}\text { Количество исследо- } \\
\text { ванных частиц }\end{array}$ \\
\hline 10 & $12-440$ & 24.3 & 25.9 & 1.3 & 350 \\
50 & $5-19$ & 10.2 & 10.9 & 1.3 & 353 \\
80 & $3-17$ & 8.9 & 9.5 & 1.3 & 308 \\
150 & $8-22$ & 13.5 & 14 & 1.3 & 241
\end{tabular}

\section{3. Результаты параметрических испытаний}

Одним из основных направлений исследований при разработке метода синтеза наночастиц является исследование зависимости среднего размера и морфологии наночастиц от технологических параметров. Необходимо определить и оптимизировать физические переменные, которые определяют зарождение и рост частиц в паровой фазе, чтобы понять процесс синтеза. Эти переменные могут быть связаны с экспериментально контролируемыми параметрами, такими, как температура испарения, общее давление в рабочей камере, тип газа, конвекции, скорости потока и геометрии камеры, производительность процесса [15].

Согласно проведенным предварительно исследованиям, свойства порошков, образующихся в плазме дугового разряда низкого давления, зависят в основном от величины давления газовой смеси в плазмохимическом реакторе $[16,17]$.

Полученные результаты с достаточной очевидностью указывают на качественное отличие порошков, полученных при разных давлениях газовой смеси. Для зависимости среднечислового диаметра частиц $d_{\text {aver }}$ от давления $p$ предложены эмпирические формулы [18]: $d_{\mathrm{aver}}=0.3 \cdot 10^{-6} p^{-3}, m$, при $p<10 \mathrm{~Pa}$; 
$d_{\text {ovar }}=0.5 \cdot 10^{-6} p^{-0.5}, m$, при $p>10$ Ра. При изменении величины давления в плазмохимическом реакторе вид функции распределения не изменяется, что говорит о преимущественно термическом характере синтеза электродуговых порошков - образование частиц за счет конденсации из паровой фазы.

На рис. 3 приведены снимки высокоразрешающей просвечивающей микроскопии, диаграммы распределения частиц и функции плотности распределения по размерам наночастиц оксида меди, полученных при различных давлениях газовой смеси. В качестве буферного газа был выбран азот.

Как следует из полученных результатов, порошок $\mathrm{Cu}_{2} \mathrm{O}$ состоит из сильно агломерированных частиц неправильной формы. На снимках присутствуют частицы размером от 5 до $50 \mathrm{~nm}$. Самые крупные частицы образуются при давлении газовой смеси 10 Ра. Во всем диапазоне давлений для частиц характерны смешанное нормальное и логарифмически нормальное распределения частиц по размерам. Логнормальное распределение характерно для частиц, полученных при давлении $10 \mathrm{~Pa}$, и, напротив, нормальное распределение в большей степени характерно для частиц, полученных при $80 \mathrm{~Pa}$.

Основные параметры вероятностного распределения частиц по размерам приведены в таблице.

В пользу предложенного механизма конденсации и смешанного вероятностного распределения частиц по размерам говорят три экспериментальных факта. Вопервых, сложный профиль линий рентгеноструктурного анализа всех полученных наноматериалов указывает на то, что распределение частиц по размерам бимодальное. Вклад в уширение спектральных линий дают еще и наночастицы со средними размерами $\sim 2 \mathrm{~nm}$. Таким образом, можно говорить о кластерном характере конденсации наночастиц в пароплазменной смеси. Вовторых, на рис. 4 представлена типичная HRTEM наночастиц оксида меди. Как видно из представленного рисунка, частицы имеют неправильную форму, кристаллическую структуру и высаженный на поверхность более мелкий конденсат размером $\sim 2 \mathrm{~nm}$, что хорошо согласуется с данными, полученными при обработке рентгенограмм. В-третьих, были проведены исследования удельной поверхности нанопорошка оксида меди методом БЭТ. Величина удельной поверхности, рассчитанная по изотерме низкотемпературной адсорбции аргона, составила $446 \mathrm{~m}^{2} / \mathrm{g}$. Если воспользоваться известным соотношением между площадью поверхности $S$, пикнометрической плотностью $\rho=8.51 \mathrm{~g} / \mathrm{cm}^{3}$ и средним размером частиц $d=6 / \rho S$, то получим $2 \mathrm{~nm}$, что хорошо согласуется с микроскопическими исследованиями.

На рис. 5 представлен график зависимости напряжения на разрядном промежутке с медным катодом от давления газовой смеси $10 \mathrm{vol} . \% \mathrm{O}_{2}+90 \% \mathrm{~N}_{2}$.

Как видно из рисунка, наблюдается постепенное снижение напряжения до точки перегиба и затем рост вплоть до максимального значения давления газовой

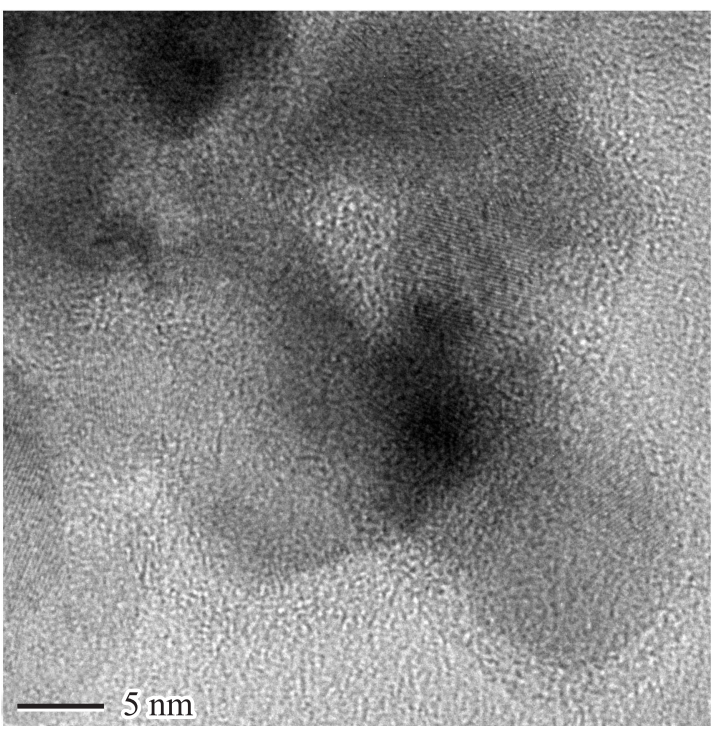

Pис. 4. HRTEM фотография наночастиц оксида меди.

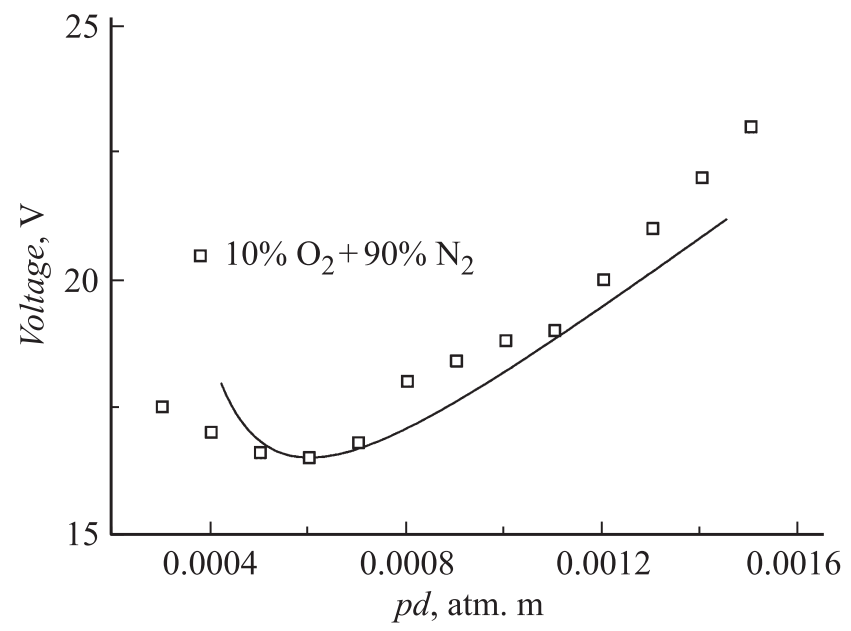

Рис. 5. Зависимость напряжения на разрядном промежутке с медным катодом от давления газовой смеси 10 vol. $\% \mathrm{O}_{2}+90 \% \mathrm{~N}_{2}$.

смеси. Поведение кривой функции напряжения на разрядном промежутке по виду напоминает зависимости среднего значения размера порошков. Необходимо отметить, что измерение напряжения на разрядном промежутке в диапазоне давлений газовой смеси от $10^{-3} \mathrm{~Pa}$ до $50 \mathrm{~Pa}$ показало несущественное влияние давления на плазменные процессы и процессы токопереноса. Однако при давлении газовой смеси свыше $50 \mathrm{~Pa}$ и вплоть до 200 Ра наблюдается практически полное совпадение поведения кривых $U(p)$ с предсказанием теории подобия.

На рис. 6 показаны результаты рентгенофазового исследования наноматериалов, полученных при испарении медного катода в кислородосодержащей среде, при различных давлениях. Рисунок показывает рентгеновские дифрактограммы наночастиц, синтезированных при дав- 


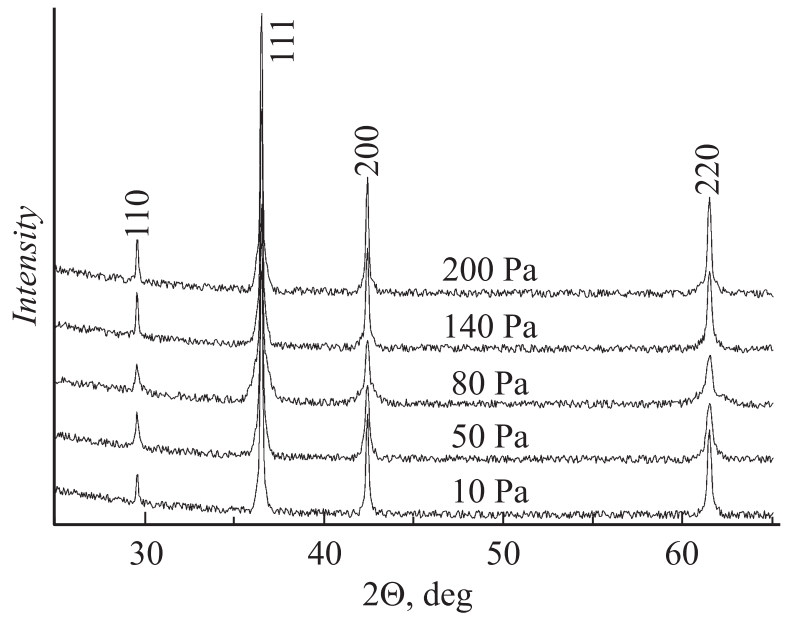

Рис. 6. Рентгенограммы нанопорошков оксида меди, полученных при различных давлениях газовой смеси $10 \mathrm{vol} . \% \mathrm{O}_{2}+$ $+90 \% \mathrm{~N}_{2}$.

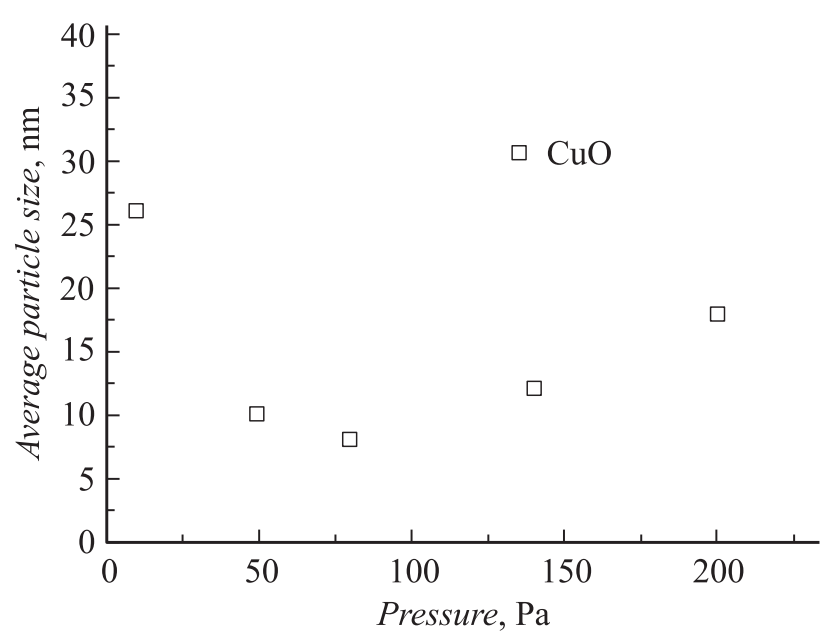

Рис. 7. Зависимость вычисленного из рентгенограмм среднего размера частиц $\mathrm{Cu}_{2} \mathrm{O}$ от давления газовой смеси 10 vol. $\% \mathrm{O}_{2}+90 \% \mathrm{~N}_{2}$.

лениях газовой смеси $10 \mathrm{vol} \% \mathrm{O}_{2}+90 \% \mathrm{~N}_{2}$ для значений $2 \theta$ в интервале от 25 до $65 \mathrm{deg}$. На дифрактограммах наночастиц ясно видны рефлексы (данные JCPDS, № 050667), соответствующие купритной структуре $\mathrm{Cu}_{2} \mathrm{O}$, пространственная группа $P n 3 m$, других кристаллических структур не обнаружено.

На рис. 7 представлены результаты исследования рентгенограмм при помощи программы PowderCell 2.4. Показана зависимость среднего размера областей когерентного рассеяния от давления различных газовых смесей.

На основании приведенной зависимости и микроскопических исследований можно заключить, что для разработки технологии получения нанопорошков оксида меди в плазме дугового разряда низкого давления ключевым параметром является давление газовой смеси. Данный параметр определяет не только механизмы ионизации в дуговом разряде, но и механизмы испарения и конденсации в высокоионизированных средах.

Работа выполнена в рамках Государственного задания Министерства образования и науки Российской Федерации на 2014-2016 г. (проект № 11.370.2014/K).

\section{Список литературы}

[1] Роко М.К., Уильямс Р.С., Аливисатос П. Нанотехнология в ближайшем десятилетии. Прогноз направления исследований / Пер. с англ. М.: Мир, 2009. 292 с.

[2] Ноздрин И.В., Галевский Г.В., Руднева В.В., Ширяева Л.С. // Изв. вузов. Черная металлургия. 2011. № 8. C. 27-32.

[3] Ноздрин И.В., Руднева В.В., Ширяева Л.С., Терентьева М.A. // Изв. вузов. Черная металлургия. 2012. № 2. C. $13-18$.

[4] Ильин А.П. // Изв. Том. политех. ун-та. 2003. Т. 306. № 1. C. $133-139$.

[5] Гусев А.И. Наноматериалы, наноструктуры, нанотехнологии. М.: Физматлит, 2005. 416 с.

[6] Ushakov A.V., Karpov I.V., Lepeshev A.A., Petrov M.I. // J. Appl. Phys. 2015. Vol. 118. N 2. P. 023907.

[7] Lepeshev A.A., Karpov I.V., Ushakov A.V., Nagibin G.E. // J. Alloys and Compounds. 2016. Vol. 663. P. 631-635.

[8] Карпов И.В., Ушаков А.В., Федоров Л.Ю., Лепешев А.А. // ЖТФ. 2014. Т. 84. Вып. 4. С. 93-97.

[9] Федоров Л.Ю., Карпов И.В., Ушаков А.В., Лепешев А.А. // Неорганические материалы. 2015. Т. 51. № 1. С. 1-5.

[10] Ушаков А.В., Карпов И.В., Лепешев А.А., Федоров Л.Ю., Шайхадинов А.А. // ЖТФ. 2016. Т. 86. Вып. 1. С. 105-109.

[11] Ушаков А.В., Карпов И.В., Лепешев А.А. // ЖТФ. 2016. Т. 86. Вып. 2. С. 105-109.

[12] Месяи Г.А., Баренгольи С.А. // Письма в ЖЭТФ. 2002. Т. 75. Вып. 6. С. 306-308.

[13] Ушаков А.В., Карпов И.В., Лепешев А.А. // Вестн. СибГАУ. 2015. T. 16. № 4. C. 983-989.

[14] Lepeshev A.A., Karpov I.V., Ushakov A.V., Fedorov L.Yu., Shaikhadinov A.A. // Intern. J. Nanoscience. 2016. Vol. 15. N 1-2. P. 1550027.

[15] Андриевский Р.А., Нужсдин А.А. // Итоги науки и техники. Серия: Порошковая металлургия. М.: Металлургия, 1986. T. 2. C. 3-64.

[16] Ушаков А.В., Карпов И.В., Лепешев А.А., Петров М.И., Федоров Л.Ю. // ФТТ. 2015. Т. 57. Вып. 5. С. 903-907.

[17] Ушаков А.В., Карпов И.В., Лепешев А.А. // ФТТ. 2015. Т. 57. Вып. 11. C. 2251-2253.

[18] Bernholc J., Phillips J.C. // J. Chem. Phys. 1986. Vol. 85. N 6. P. 3258-3267. 